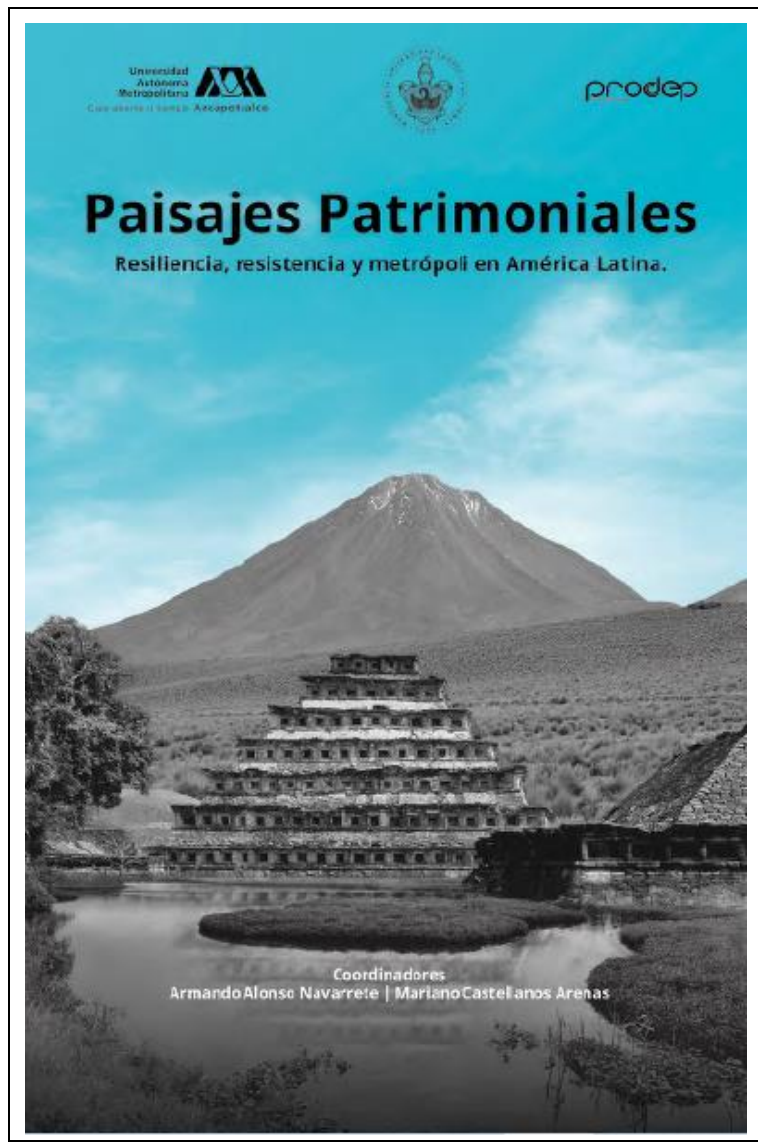

Rivera Juárez, Frida Itzel (2020).

Una aproximación a la dimensión patrimonial del paisaje en la comunidad de San Pedro Atlapulco, Estado de México.

p. $209-232$

En:

Paisajes patrimoniales. Resiliencia, resistencia y metrópoli en América Latina. V. Paisaje y gestión / Armando Alonso Navarrete y Mariano Castellanos Arenas, coordinadores. Ciudad de México: Universidad Autónoma Metropolitana, Unidad Azcapotzalco, 2020.

Fuente: ISBN 978-607-28-1996-2 (versión electrónica). Relación: http://hdl.handle.net/11191/7575

\begin{tabular}{|c|c|c|}
\hline $\begin{array}{c}\begin{array}{r}\text { Universidad } \\
\text { Autónoma } \\
\text { Metropolitana }\end{array} \\
\text { Casa abierta al tiempo Azcapotzalco } \\
\text { Universidad Autónoma Metropolitana } \\
\text { Unidad Azcapotzalco } \\
\text { https://www.azc.uam.mx/ }\end{array}$ & $\begin{array}{l}\begin{array}{r}\text { División de Ciencias y Artes para } \\
\text { el Diseño }\end{array} \\
\text { https://www.cyad.online/uam/ }\end{array}$ & $\begin{array}{l}\begin{array}{l}\text { Departamento del Medio } \\
\text { Ambiente }\end{array} \\
\text { http://www.medioambiente.azc } \\
\text {.uam.mx/jefatura.html }\end{array}$ \\
\hline & $\begin{array}{c}\text { Área de Investigación } \\
\text { Arquitectura del Paisaje } \\
\text { Área de Investigación } \\
\text { Arquitectura del Paisaje }\end{array}$ & \\
\hline
\end{tabular}

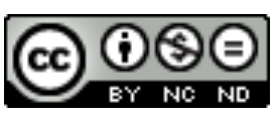

Excepto si se señala otra cosa, la licencia del ítem se describe como

Atribución-NoComercial-SinDerivadas

https://creativecommons.org/licenses/by-nc-nd/4.0/

D.R. C 2020. Universidad Autónoma Metropolitana, Unidad Azcapotzalco, División de Ciencias y Artes para el Diseño, Departamento del Medio Ambiente, Área de Investigación Arquitectura de Paisaje. Se autoriza copiar y redistribuir el material en cualquier medio o formato, siempre y cuando se den los créditos de manera adecuada, no puede hacer uso del material con propósitos comerciales, si remezcla, transforma o crea a partir del material, no podrá distribuir el material modificado. Para cualquier otro uso, se requiere autorización expresa del titular de los derechos patrimoniales. 


\section{Una aproximación a la dimensión patrimonial del paisaje en la comunidad de San Pedro Atlapulco, Estado de México. ${ }^{1}$}

Frida Itzel Rivera Juárez Comunidad de Geógrafas - Geobrujas. fridaitzelriverajuarez@gmail.com

Resumen: Nuestros paisajes hoy se enfrentan cotidianamente a la voracidad del capitalismo neoliberal, este sistema socio-económico genera desigualdades abismales y pone en riesgo el futuro de nuestros territorios. Ante este panorama, el desarrollo de metodologías participativas centradas en rescatar el conocimiento territorial e histórico local, se vislumbra como una oportunidad para conocer la valoración social del paisaje. El objetivo es integrar la dimensión patrimonial del paisaje a la gestión territorial, en un proceso incluyente a través del diálogo entre la ciencia, la administración pública y la sociedad civil.

Palabras clave: territorio, metodologías participativas, dimensión patrimonial del paisaje, gestión territorial.

Abstract: Our landscapes today face daily the voracity of neoliberal capitalism, this socio-economic system generates abysmal inequalities and puts the future of our territories at risk. Given this panorama, the development of participatory methodologies focused on rescuing local territorial and historical knowledge is seen as an opportunity to know the social assessment of the landscape. The objective is to integrate the heritage dimension of the landscape into territorial management, in an inclusive process through dialogue between science, public administration and civil society.

Keywords: territory, participatory methodologies, heritage dimension of the landscape, territorial management.

\section{La integración del Paisaje Patrimonial en la gestión territorial.}

El paisaje hoy es una preocupación de carácter multidisciplinaria. Es un concepto polisémico y multidimensional, pero siempre una expresión visible y sensible de los procesos sociales y territoriales. Históricamente, la geografía se ha aproximado al paisaje desde diversos puntos de vista, como por ejemplo los estudios naturalistas impulsados desde la escuela

\footnotetext{
1 La investigación original corresponde a una tesis para obtener el grado de licenciatura, “Paisajes comunitarios, una aproximación a la dimensión patrimonial del paisaje: El caso de San Pedro Atlapulco en el estado de México". Asesor: Dr. Martín Checa-Artasu. Lector: Dr. Pere Sunyer Martín. (2017).

En el año 2019 la Asociación Mexicana de Estudios Rurales A.C. le otorgó el Premio a la Mejor Investigación sobre el Campo Mexicano en la categoría de Tesis de Licenciatura.
} 
rusa y alemana, o los de corte cultural desarrollados desde la Universidad de California con Carl Sauer. En las últimas décadas, las reflexiones sobre el paisaje han sido producto "de la moda ecológica-ambientalista que sacude a la sociedad de consumo" (Bertrand y Bertrand, 2007:236), o bien se han reafirmado aspectos esteticistas y pseudo-culturales asociados al enfoque propiciado desde instancias internacionales como la Convención del Patrimonio de la Humanidad.

Esta visión patrimonialista choca con los enfoques más recientes respecto con la protección del paisaje, los cuales integran la experiencia, percepción y valorización de quienes los habitan; en este sentido el Convenio Europeo del Paisaje (2000), en su Artículo 1, lo define como "cualquier parte del territorio tal y como la percibe la población, cuyo carácter sea el resultado de la acción y la interacción de factores naturales y/o humanos"; un aspecto fundamental en el cambio de visión sobre la dimensión patrimonial del paisaje, "significa que son mucho más próximos al ser humano, al punto de situarse en donde alguna persona esté, perciba y valore aquello que está observando". (Sunyer, 2017:31).

Para aproximarnos ${ }^{2}$ a una definición del paisaje patrimonial, fue obligatorio hacer una revisión histórica del concepto de patrimonio, reconociendo su origen en el ámbito privado y su tránsito a ser un elemento clave para la conservación del espacio público; así mismo reflexionar sobre las diversas dimensiones del patrimonio con énfasis en el aspecto político del mismo de una forma crítica: tradicionalmente en la gestión territorial, nos enfrentamos a la conceptualización del patrimonio por parte de las instituciones, como la Organización de las Naciones Unidas para la Educación, la Ciencia y la Cultura (UNESCO) que enaltecen un $<<$ valor excepcional, monumental, o de belleza escénica>>, jerarquizan y definen el valor patrimonial según sus criterios, los cuales desconocen el ámbito local, por lo tanto, no reflejan las preocupaciones de los actores locales.

Se deja de lado el papel de la sociedad en la construcción diaria del paisaje, en lo que podría denominarse la "producción del paisaje". En este sentido, Pere Sunyer (2017) en una revisión de distintos documentos de trascendencia para la dimensión patrimonial del paisaje en el ámbito internacional, nos explica el contexto proteccionista en el que se ha

2 Utilizamos el uso de la primera persona del plural a lo largo de la redacción del documento, porque lo consideramos un posicionamiento crítico al desarrollo científico de las ciencias sociales, escribimos nosotros, porque pensamos que esta investigación es parte de un grito por el cambio social y “¿desde qué otro lugar podemos comenzar? En tanto escribir/leer es un acto creativo, es inevitablemente, el acto de un nosotros. Comenzar en tercera persona no es un punto de partida neutral, puesto que ya supone la supresión del nosotros" (Holloway, 2005:8). Además, hablar de nosotros implica también otorgar un reconocimiento a la voz, tiempo y disposición que los habitantes de la comunidad de Atlapulco mostraron durante la producción de la investigación. 
desarrollado este concepto desde la perspectiva occidental. En su análisis explica las transformaciones que han logrado que el paisaje hoy tenga un alcance social más profundo. "Proteger los paisajes significa extender esa protección al territorio donde se ubica y también a la sociedad que los ha creado, a su cultura y sus tradiciones" (Sunyer, 2017:35).

Otro elemento para señalar de forma relevante en el Convenio Europeo del Paisaje (2000), es su consideración como instrumento jurídico, “donde el paisaje es elevado a la categoría de bien común y, por tanto, sujeto a disponibilidad de los ciudadanos, dada esa categoría y lo que la misma implica (...) De esa manera, el debate en torno al derecho al paisaje pone sobre la mesa otra afirmación. El paisaje es y puede ser considerado como un bien común, entendido éste como recurso económico, social y cultural, poseído por un colectivo humano más o menos amplio que lo considera parte de su identidad" (Checa-Artasu, 2017:49).

La investigación de Martín Checa-Artasu (2014) acerca de la presencia del concepto de paisaje en la legislación mexicana, señala su limitada consideración y su indefinición jurídica, argumento que coincide con el preámbulo de la Carta Mexicana del Paisaje (2011), elaborada por la Sociedad de Arquitectos Paisajistas de México, en la cual se dice que "desde la promulgación de la Ley Federal de Monumentos y Zonas Arqueológicos, Artísticos e Históricos en 1972, y posteriormente la incorporación de un apartado sobre protección de áreas naturales en la Ley General de Equilibrio Ecológico y Protección al Ambiente (LGEEPA) en 1988, los esfuerzos legislativos han seguido caminos paralelos para la protección y conservación de paisajes culturales y naturales, sin que exista a la fecha un concepto genérico que abarque las diversas expresiones del patrimonio paisajístico".

Ante este panorama, la consideración de los paisajes patrimoniales se vislumbra como una oportunidad de interlocución entre la ciencia, la gestión territorial y la sociedad civil, para contribuir al desarrollo de una organización territorial más equilibrada y justa; "porque mirar el paisaje como una representación cultural y como un sujeto político producido de una determinada manera, es también un reclamo que aboga por el derecho a disponer de paisajes con unas condiciones específicas, porque éstos son sinónimo de una determinada calidad de vida y la demanda de un mundo deseable y mejor para las generaciones venideras, especialmente en términos ambientales, éticos y políticos" (Abarca, Campos, 2013:75, citado por Checa-Artasu, 2017:46).

El interés por definir los paisajes patrimoniales se debe a la necesidad de integrar sus diversas dimensiones y características, con la intención de proyectar instrumentos para la gestión territorial adecuados al ámbito 
local; en ellos se debe posicionar de forma preponderada la valorización de las comunidades que habitan cotidianamente los paisajes.

Por dimensión patrimonial del paisaje entendemos que en él se conservan los usos y significados históricos del territorio y de los elementos que contiene, que se expresan también en las tensiones existentes entre los diversos grupos sociales y sus concepciones. En este sentido, se podría decir que el paisaje es marco de vida, que es significado, valorado, producido y reproducido a través de las dinámicas sociales entre los grupos que cohabitan en el territorio. Tales dinámicas pueden conllevar asimetrías en el ejercicio de poder y en el proceso de toma de decisiones que conducen a transformaciones espaciales $\mathrm{y}$, en consecuencia, a paisajes claramente diferenciados.

El objetivo de este documento es exponer algunos resultados de investigación que corresponden a un trabajo más amplio y profundo; el trabajo se enmarca en una aproximación metodológica enmarcada en la Investigación-Acción-Participativa (IAP) ${ }^{3}$, con el objetivo de caracterizar la dimensión patrimonial del paisaje en San Pedro Atlapulco (Ocoyoacac, Estado de México), localidad de estudio que como veremos vive mayoritariamente de ese bien patrimonializable, los paisajes.

Como parte de los primeros resultados, se caracterizan los elementos estructurantes del territorio y el paisaje, para posteriormente hacer una delimitación de Unidades de Paisaje. Se entenderá por “Unidad de Paisaje el área geográfica con una configuración estructural, funcional o perceptivamente diferenciada, única y singular, que ha ido adquiriendo los caracteres que la definen tras un largo período de tiempo. Se identifica por su coherencia interna y sus diferencias con respecto a las unidades contiguas" (Muñoz y Díez, 2012:66).

La integración del patrimonio paisajístico de la comunidad de San Pedro Atlapulco a las unidades de paisaje, pretende resaltar la oportunidad en cuanto a la defensa y mejora de los territorios que representa preponderar las formas de producción, valorización y percepción del paisaje de la población local; al definir guías para una adecuada gestión territorial, que considere y respete sus elementos constitutivos.

\footnotetext{
3 Un esquema ligado a la Educación Popular, "una corriente pedagógica latinoamericana que combina la ética con la política emancipadora, con una posición crítica hacia el orden social imperante contribuyendo a que sectores y movimientos populares se constituyan en sujetos al ampliar su horizonte y visión del futuro desde procesos dialógicos y participativos" (Torres, 2007, citado por Ortiz y Borjas, 2008:619). Con una base epistemológica, la producción de conocimiento no se considera neutral, "siempre responde a la situación y a los intereses de los sujetos que lo producen desde su base social; por ello, Orlando Fals Borda sugiere que «es necesario descubrir esa base para entender los vínculos que existen entre el desarrollo del pensamiento científico, el contexto cultural y la estructura de poder de la sociedad»" (Fals, 1980:72, citado por Ortíz y Borjas, 2008:617).
} 


\section{El territorio y el paisaje en la dialéctica espacial.}

La relación entre el patrimonio y la gestión territorial, se puede interpretar mediante la dialéctica espacial que se despliega entre el territorio y el paisaje como conceptos distintos que resultan complementarios e indisociables; en la actualidad del pensamiento geográfico, el territorio es un elemento activo en las relaciones sociales, es base fundamental de la reproducción de la vida a nivel biológico, cultural y social, tiene un papel decisivo en el desarrollo de nuestras identidades, filosofías y cosmovisiones.

El territorio sintetiza en sí mismo un carácter ambiental y social, cultural y natural, "es el espacio geográfico adscrito a un ser, a una comunidad, a un ente de cualquier naturaleza, física o inmaterial: el espacio de vida de un animal, el área de aparición de una especie vegetal, el ámbito de difusión de una lengua o de cualquier otra práctica social, etc. Cuando se atribuye a un grupo humano complejo (un pueblo, una nación, una sociedad) se convierte en uno de los integrantes fundamentales de su proyecto común: en soporte y recurso básico, ámbito de vida, paisaje propio e invariante en la memoria personal y colectiva. En definitiva, es el espacio geográfico en el que se vive y que corresponde manejar y administrar para bien de los individuos y del conjunto de la comunidad" (Zoido, 1998:20).

Definir la relación del paisaje con la multidimensionalidad del paisaje, inevitablemente nos lleva al análisis del espacio geográfico. El geógrafo Milton Santos (2000), en su teoría crítica, influenciado por el materialismo dialéctico, ha contribuido de forma trascendental al análisis de la categoría de espacio, como un "hecho social", siendo, que "el espacio está formado por un conjunto indisoluble, solidario y también contradictorio, de sistemas de objetos y sistemas de acciones, no considerados aisladamente, sino como el contexto único en el que se realiza la historia" (Santos, 2000:54).

De tal manera que, en esta dialéctica espacial producto de la interacción de los sistemas de objetos y sistemas de acciones, entre la sociedad, el tiempo y el espacio geográfico es posible "reconocer algunas categorías analíticas internas. Entre ellas están el paisaje, la configuración territorial, la división territorial del trabajo, el espacio producido o productivo, las rugosidades y las formas-contenido" (Santos, 2000:19). El espacio geográfico se muestra así, como un hecho social inmerso en un presente, envuelto por el pasado y el futuro, "el espacio humano es síntesis, siempre provisional y siempre renovada de las contradicciones y la dialéctica social" (Santos, 2000:90).

De acuerdo con lo anterior, el paisaje y el territorio son categorías que contribuyen a dar forma y sentido al espacio como "hecho social". El mismo autor señala que, "en realidad, paisaje y espacio son siempre un palimpsesto donde mediante acumulaciones y sustituciones, la acción de 
las diferentes generaciones se superpone. El espacio constituye la matriz sobre la cual las nuevas acciones sustituyen a las acciones pasadas. Es, por lo tanto, presente porque es pasado y futuro" (Santos, 2000:87).

El paisaje es entonces la expresión que adquiere un territorio, "es un fenómeno que se manifiesta en la superficie de la Tierra, es un hecho territorial, expresión última o actual de una larga historia de interacción entre las diferentes esferas que se encuentran en la faz de la Tierra" (Sanz, 2000:282). El paisaje es una muestra de la configuración territorial en un momento dado, pero no se reduce a su apariencia, ni es estática, sino que se explica por medio del conocimiento de su estructura y funcionamiento material e inmaterial, objetivo y subjetivo, personal y colectivo.

En consecuencia, con lo que hemos explicado respecto al paisaje y el territorio, nuestra investigación suscribe que los paisajes se definen como marcos de vida, como formas y experiencias; el paisaje sería así un concepto resultado de la interacción de diversos factores y subsistemas de organización socio-ecológica, económica, territorial, cultural y estética de los pueblos, es decir una concepción unitaria del conjunto; “el paisaje nos rodea como nuestro marco, pues en el paisaje se nace, se vive y se muere. Este marco es también medio, es circunstancia, es referencia y pensamiento. El paisaje nos nutre física y espiritualmente" (Martínez de Pisón, 2010:403).

Por lo tanto, el paisaje como asimilación espiritual del mundo, es también un flujo dialéctico de información entre el territorio y la sociedad, existe "una correspondencia entre el paisaje, el territorio y la sociedad que en él vive, creando una relación que puede interpretarse en términos geográficos. Una relación que es el reflejo de las decisiones tomadas a nivel individual y colectivo, y de las tensiones que en el seno de la sociedad se producen, capaces de crear, modificar o destruir territorios" (Checa-Artasu, 2017:45).

De esta manera el territorio al igual que el paisaje se proyectan en diversas escalas, formas y manifestaciones, sin olvidarnos de la dialéctica espacial, “en el territorio está inscrita la historia: en el medio físico la historia de la Tierra, en el medio humanizado la historia de la Humanidad. El territorio está construido por el tiempo, pero a escalas temporales diferentes: tiempos de la naturaleza, y tiempos de los hombres" (Capel, 2016:16).

En síntesis, para comprender la relación complementaria entre paisaje, territorio y sociedad, hay que pensar el paisaje geográfico como algo complejo, constituido por formas y relaciones, huellas y signos, artificiales y naturales, por una diversidad temporal y de escala, es decir, los paisajes son "las formas que adquieren los sistemas territoriales, la concreción formal de la realidad espacial, no sólo sus vistas, sino su materialidad, 
las agrupaciones, organizaciones de constituyentes geográficos diversos y cartografiables, cuyas configuraciones resultan de un sistema de relaciones" (Martínez, 2008:132).

La óptica multidisciplinaria, interdisciplinaria y transdisciplinaria en geografía, nos permite mirar el territorio y el paisaje como realidades complejas en las cuales se conectan conocimientos que pertenecen a diversas áreas del conocimiento; para lo cual se vuelve imprescindible la consideración de un enfoque socio-espacial y multiescalar que nos conduzca a distinguir y comprender las dinámicas territoriales y sociales que en gran medida se muestran a través de las transformaciones en el paisaje.

Los paisajes en conjunto con el territorio son legados en la memoria colectiva, un eje estructural de las comunidades, constituido por una dimensión temporal y espacial específica en un "entendimiento del mismo concepto reelaborado a través de los siglos que contiene, más o menos visibles, las huellas de las distintas culturas y sociedades que lo han ocupado, manejado y dejado evidencia de los valores utilitarios y simbólicos, que fueron atribuidos a un determinado territorio en distintos momentos" (Zoido, 2012:628).

\section{Metodologías participativas: rutas al Paisaje Patrimonial.}

En términos prácticos el paisaje patrimonial resulta un desafío para los especialistas y todos los que se interesen en el tema. Integrar la dimensión patrimonial del paisaje en la gestión del territorio es un camino poco recorrido, en el cual, la caracterización del paisaje va de la mano con el reconocimiento de una identidad territorial propia y dinámica; es decir, el paisaje "ha dejado de entenderse como sólo un elemento a conservar para ser un elemento a proteger, gestionar y rehabilitar; y que ha pasado de sólo considerar la excepcionalidad de unos paisajes concretos para atender el paisaje desde lo cotidiano" (Checa-Artasu, 2017:49).

En consecuencia, la vinculación del paisaje patrimonial con la gestión del territorio necesita concretar indicadores que ayuden a sistematizar su contenido ambiental, social, y cultural; al respecto, consideramos conveniente utilizar como guía para la aproximación metodológica, el esquema teórico del Sistema GTP: Geosistema-Territorio-Paisaje, formulado por Claude y Georges Bertrand.

Esta propuesta nos auxilia en la jerarquización sistémica del paisaje en subsistemas. Para los fines de esta investigación se utilizó el concepto de geosistema no precisamente como una escala de análisis, sino como la descripción secuencial y relacionada de los elementos ambientales y antrópicos de nuestra zona de estudio; elementos estructurantes del 
territorio que fueron integrados por medio del análisis de productos cartográficos ${ }^{4}$. Con ello compensamos lo que en la metodología de Muñoz y Díez (2012) se señala como organización del paisaje.

Haciendo un esfuerzo por mantenernos dentro del esquema teórico que propone la pareja Bertrand (Bertrand y Bertrand, 2007) a través del Sistema GTP; y retomando la Investigación-Acción-Participativa, elegimos construir una aproximación metodológica de carácter participativo; el primer contacto que tuvimos con la comunidad agraria de San Pedro Atlapulco fue a través de la organización del Taller de Ordenamiento Territorial Comunitario, realizado de septiembre a diciembre del 2012, el cual nos permitió elaborar un diagnóstico sobre el tema; posteriormente realizamos distintos recorridos en campo con el acompañamiento de algunos integrantes del "Colectivo 26 de Agosto de 19725", quienes nos ayudaron a definir de mejor manera el camino de la investigación.

Para la sistematización y caracterización de los paisajes de Atlapulco tomamos como pauta la "Guía metodológica. Estudios del paisaje" (Muñoz y Díez, 2012), principalmente recuperamos la propuesta para la delimitación de unidades de paisaje (ver Cuadro 1). Es importante considerar, que si bien cada unidad de paisaje se delimitan como un área con características únicas que representan un carácter paisajístico propio, asimismo "diferentes unidades del paisaje pueden poseer una misma organización de los componentes del paisaje dando lugar a tipos de paisaje" (Muñoz y Díez, 2012:66); de esta forma, los tipos de paisaje pueden incluir dos o más unidades de paisaje, es decir, varias unidades de paisaje pueden pertenecer a un mismo tipo de paisaje, lo que otorga el carácter de unidad es la continuidad que tienen sobre la superficie territorial, mientras que los tipos de paisaje se configuran a partir de los componentes más significativos del paisaje.

4 Con datos referentes a geomorfología, clima, hidrología, vegetación, edafología y usas se suelo principalmente.

5 Este grupo colectivo ha sido parte fundamental para la defensa del territorio en la comunidad de Atlapulco. 


\begin{tabular}{|l|l|}
\hline \multicolumn{1}{|c|}{$\begin{array}{c}\text { Ejes para la } \\
\text { caracterización }\end{array}$} & \multicolumn{1}{c|}{ Criterios a considerar } \\
\hline Evolución del paisaje & $\begin{array}{l}\text { ¿Cómo ha sido el paisaje en el pasado?, ¿ha cambiado o } \\
\text { por el contrario ha permanecido inalterado?, ¿cuáles han } \\
\text { sido las causas?, ¿cuáles son las tendencias de cambio para } \\
\text { el futuro? }\end{array}$ \\
\hline Organización del paisaje & $\begin{array}{l}\text { ¿Cuáles son los rasgos y elementos que definen el ámbito } \\
\text { de estudio?, ¿cómo se estructuran?, ¿qué relaciones } \\
\text { formales, visuales y funcionales guardan entre ellos? }\end{array}$ \\
\hline Recursos paisajísticos & $\begin{array}{l}\text { ¿Qué recursos paisajísticos existen?, ¿de qué naturaleza } \\
\text { son? }\end{array}$ \\
\hline Conflictos paisajísticos & ¿Qué problemas existen?, ¿qué amenazas encontramos? \\
\hline Unidades del paisaje & $\begin{array}{l}\text { ¿Qué unidades de paisaje podemos identificar en el } \\
\text { territorio objeto de estudio? }\end{array}$ \\
\hline
\end{tabular}

Cuadro 1. Criterios y ejes para la delimitación y caracterización de las unidades de paisaje. Fuente: Elaboración propia con base en Muñoz y Díez, 2012:58.

En la delimitación de unidades de paisaje es fundamental poner atención en los patrones de ocupación del territorio, en este sentido, siguiendo con Muñoz y Díez (2012), la delimitación requiere “primeramente, la identificación de las áreas que poseen un mismo carácter paisajístico, y más tarde, la acotación de estas zonas, atendiendo a las transiciones y fronteras que se producen entre diferentes patrones de paisaje" (Muñoz y Díez, 2012:67). En este caso las unidades de paisaje son una síntesis operativa del trabajo realizado a lo largo de la investigación que permiten comprender mejor el funcionamiento del territorio, con el objetivo de ampliar las posibilidades de gestión de éste; la sistematización de la información territorial por medio de unidades de paisaje puede clarificar los escenarios para la toma de decisiones.

Para realizar la caracterización de la evolución del paisaje nos auxiliamos con fotografías históricas y fotografías actuales que nos permitieron contrastar la información de forma visual y observar las transformaciones en el paisaje, así como sus tendencias de cambio.

La identificación y el reconocimiento de los recursos paisajísticos nos conduce a una propuesta de delimitación de unidades de paisaje más precisa y con mayor contenido útil para la toma de decisiones, en vista de que "los recursos paisajísticos son aquellos elementos del paisaje que merecen una especial consideración por su interés ambiental, cultural, visual y social" (Muñoz y Díez, 2012:78); también estos son utilizados en la detección de conflictos paisajísticos, tomando como punto de partida las tendencias de cambio reconocidas previamente en la evolución histórica del paisaje. Al relacionar la evolución y organización del paisaje, la identificación de recursos y conflictos paisajísticos, concretamos la delimitación de unidades de paisaje. 


\section{Resultados. La dimensión patrimonial del paisaje en San Pedro Atlapulco.}

La comunidad agraria de San Pedro Atlapulco está enclavada en las estribaciones de la Sierra de las Cruces, a una altitud de 2,990 msnm. Desde hace cincuenta años aproximadamente, sus principales ingresos familiares provienen de las actividades turísticas que se organizan en lo que ellos denominan "valles". Desde la década de 1940, la comunidad - como han señalado Neptalí Monterroso et al. (2009) - comenzó a relacionarse con el Parque Nacional La Marquesa. A los pocos años, en 1960, se iniciaron las actividades en lo que hoy se conoce como Valle del Conejo al que se sumó el hoy muy frecuentado Valle del Potrero.

Oficialmente a los "valles", se les conoce como Centros recreativos, pero los lugareños de Atlapulco y de las comunidades vecinas como San Jerónimo Acazulco, Salazar y San Miguel Almaya siguen Ilamándoles "valles turísticos", pese a que en muchas ocasiones ni son valles ni es propiamente el turismo el que visita tales lugares. Son más bien centros de recreación y excursionismo ${ }^{6}$, en los que el visitante, aparte de degustar la sabrosa cocina local, puede realizar paseos a caballo, manejar cuatrimotos, practicar diversas modalidades deportivas de riesgo (tirolesa, escalada), entre muchas otras.

Uno de los principales atractivos de estos valles es su extraordinaria ubicación, a los pies de la vertiente occidental de la Sierra de las Cruces. En sus paisajes se mezclan las masas boscosas con espacios rurales y las zonas de pasto ganaderas. La riqueza hídrica del lugar se percibe a primera vista: son varios los arroyos, riachuelos y manantiales que refrescan este lugar. La comunidad y todo su territorio se sitúa en el Eje Neovolcánico Transversal, concretamente en la subprovincia fisiográfica de Lagos y volcanes del Anáhuac.

Debido al origen volcánico de la región, se aprecian diversas formas asociadas al mismo, como abundantes edificios volcánicos inactivos y un derrame de lava que configura un extenso pedregal, cubierto hoy por un bosque de encinos. El ecosistema dominante en San Pedro Atlapulco, así como en las localidades próximas, es el forestal, concretamente, el bosque de oyamel (Abies religiosa), asociado a unos suelos de origen

6 Hacemos hincapié en que, si bien en los valles de Atlapulco existen actividades con fines de ocio, la mayoría de estas actividades son realizadas por visitantes de un día o unas horas. El diccionario de geografía aplicada y profesional define el excursionismo, como "aquellos visitantes de un día, al que deben prestarse servicios que le motiven su deseo de volver con una estancia de mayor duración (López, 2015:609); a diferencia del turismo, en el cual “la Organización Mundial del Turismo destaca que, para ser considerada turista, una persona deber pernoctar como mínimo una noche en el lugar de visita" (López, 2015:599). Por ello, el fenómeno de ocio en Atlapulco no se define propiamente como turismo, aunque coloquialmente los lugareños así lo llaman. 
volcánico $y$, en consecuencia, ricos en nutrientes, con una elevada permeabilidad. Sin embargo, su pronunciada pendiente y su joven origen no permiten un aprovechamiento agrícola sustancioso y éste se reduce a las zonas de lomerío.

Una característica de la localidad de estudio es su proximidad a dos de los centros urbanos más importantes del país: la Zona Metropolitana de la ciudad de México, y la Zona Metropolitana de Toluca (ver Ilustración 1), esto le otorga a San Pedro Atlapulco tanto ventajas como inconvenientes. Entre ellas está el flujo continuo de visitantes que encuentran en las tierras de la comunidad, un espacio de gran valor para desarrollar actividades de ocio, deportivas o simplemente de disfrute de la naturaleza. Asimismo, las tierras de Atlapulco ofrecen, servicios ambientales a ambas metrópolis, los principales son la aportación directa e indirecta de agua a la ciudad de México y a la de Toluca a través de sus manantiales; una superficie forestal extensa que sirve de contrapunto a la deforestación y la contaminación urbana; y una alta calidad de sus paisajes.

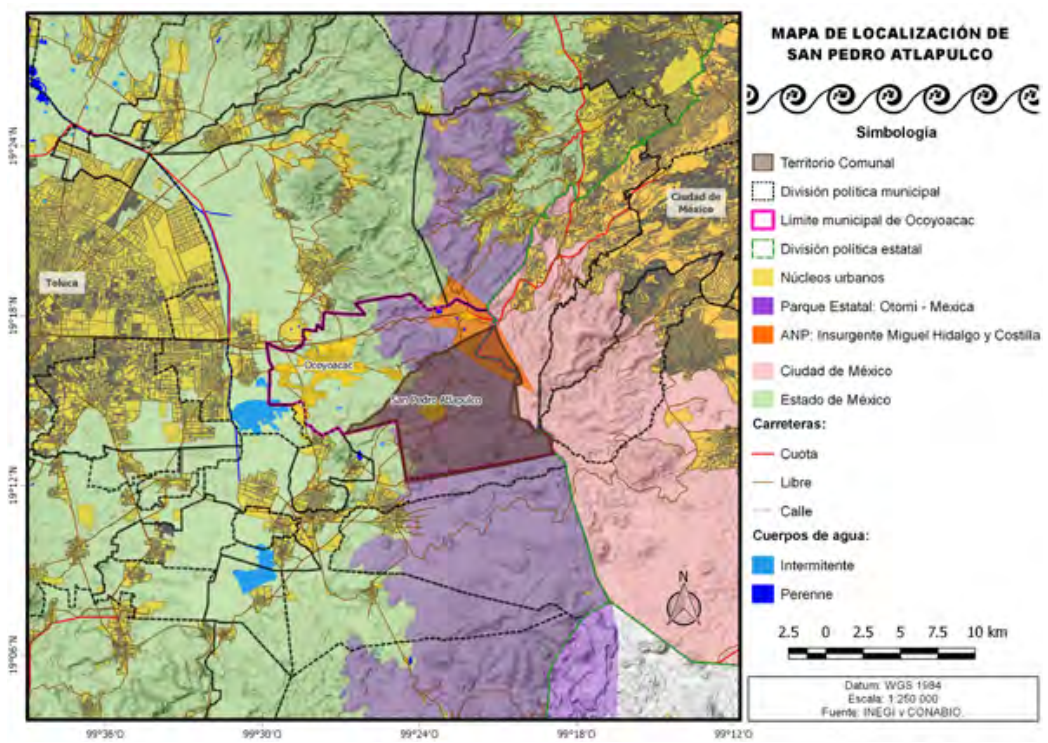

Ilustración 1. Mapa de localización de San Pedro Atlapulco, Estado de México. Fuente: Elaboración propia.

Un aspecto fundamental para entender la situación de Atlapulco es el derivado del "alto grado de vinculación económica, funcional y urbana" (Sunyer y Monterroso, 2016:11) con ambas metrópolis. Parte de la población de esta localidad trabaja, vive temporalmente y compra productos en ellas, parte de las consecuencias de la consolidación de la gran megalópolis 
del centro del país (Garza, 2010:41). De ella emanan algunos de los inconvenientes que ha tenido la población de Atlapulco, tal como han puesto de relieve Sunyer y Monterroso (2016) sus tierras y recursos son de gran interés para agentes externos a la comunidad.

Sin embargo, no es Atlapulco un caso aislado. La misma dinámica se está reproduciendo en muchos parajes de comunidades aledañas a este gran ámbito ya megalopolitano. En consecuencia, reflexionamos que, bajo este proceso, las transformaciones del paisaje tienden a ser aceleradas, de carácter urbano y bajo un modelo económico-cultural establecido desde el capitalismo en su fase de globalización neoliberal.

Nos encontramos inmersos en una dinámica en la cual el crecimiento poblacional y la expansión de la urbanización exigen cada vez más espacio y recursos para su desarrollo, asimismo lugares para la recreación y el disfrute del tiempo libre. En este sentido la naturaleza se ha convertido en un objeto de consumo.

Frente a esta serie de acontecimientos la identificación de los valores patrimoniales en el paisaje de San Pedro Atlapulco, representa una oportunidad para comprender los rasgos del pasado y las tendencias de cambio en el territorio.

San Pedro Atlapulco tiene su origen como un pueblo Hñähñú (otomí). El primer topónimo del lugar en otomí es "Em'Bohigui" o "Em 'bosh 'kí" que significa "lugar donde hay agua en bosque", existe otra acepción donde se afirma que Atlapulco era conocido también como "N'Donhuani", "el gran mirador" por situarse en el vértice más alto del Valle de México y valle de Toluca. (Vera, 2000 citado en Cervantes, 2010). Después de la conquista azteca se denomina al pueblo como Atlapulco que en náhuatl significa "lugar rodeado de agua" o "lugar donde brota el agua". Su toponimia es reflejo de la identidad territorial del lugar.

En la memoria colectiva del pueblo, la gente de Atlapulco recuerda que llevaba ofrendas a los montes, principalmente a donde había manantiales y cuevas porque estos son lugares relacionados al origen de la vida. Esto se refuerza con el simbolismo del altepetl mesoamericano, "el propio metónimo altepetl "agua-montaña", evoca una gama amplia de metáforas que aportaban, y todavía aportan, significados y razón de ser a la vida de la comunidad mesoamericana"7 (Bernal y García, 2006:67).

El culto al agua y a los cerros en Atlapulco permanece en el tiempo, si bien los rituales han cambiado por el colonialismo europeo y el adoctrinamiento de la iglesia católica, el sincretismo que encontramos en la comunidad

7 "Una de las mejor conocidas es la que compara al altepetl con una <<olla llena de agua>>" (Sahagún (1981) [1582]), III, pp. 344-345 citado en Bernal y García, 2006:67). 
reafirma la existencia de una cosmovisión ligada al pensamiento indígena. Basta poner atención a su sistema agroforestal heredado y al calendario agrícola-ritual por el cual se rigen, este no se concibe únicamente como un sistema productivo; la milpa es un espacio sagrado, el ciclo agrícola encierra en sí mismo una ritualidad relacionada a la vida, el maíz, la fertilidad, la tierra, los cerros, las montañas, la lluvia y las nubes. Otro ejemplo de ello es, el papel de Atlapulco en la sacralidad del espacio regional, es un paraje importante en el camino de los peregrinos al Santuario de Nuestro Señor de Chalma, además de un lugar de destino para la gente de Atlapulco durante la celebración del nacimiento de Quetzalcóatl ${ }^{8}$.

El origen indígena de Atlapulco explica también la configuración actual del régimen de propiedad comunal, lo cual define una forma de organización socio-cultural específica. Las luchas por la defensa de la tierra y el agua son elementos que otorgan identidad a la comunidad y aparecen en la memoria colectiva de forma constante como un símbolo en el paisaje; un ejemplo emblemático es, la Resolución Presidencial del 14 de agosto de 1946, donde gracias al reconocimiento de los títulos primordiales ${ }^{9}$, se resuelve un conflicto por la posesión de tierras que en 1936 generó el decreto de Parque Nacional.

En el desarrollo histórico de Atlapulco, se identifican grandes transformaciones territoriales asociadas a las formas históricas de producción y reproducción de la vida, y estas se reflejan en el paisaje, conocer la historia económica de la comunidad nos ayuda a explicar las formas de gestión que han convivido en el territorio. El concepto de "larga duración" de Fernand Braudel nos es útil para entender los procesos históricos que han modelado los territorios, y en nuestro caso nos permite analizar los sistemas productivos por los cuales la comunidad ha transitado (Ver Cuadro 2).

8 El 21 de diciembre, cada año desde tiempos inmemoriales, el pueblo de Atlapulco camina rumbo a Chalma, llevan maíz y a los santos patrones. En el calendario-ritual de San Pedro Atlapulco, este día se señala como el nacimiento de Quetzalcóatl, también el solsticio de invierno; se encuentra justo después de la fiesta del Día de todos los Santos (celebrada el 31 de octubre, 1 y 2 de noviembre), que simboliza el cierre del ciclo agrícola; la peregrinación a Chalma anuncia que ya todos levantaron la cosecha y cortaron el zacate de la milpa.

9 Nos referimos a la concesión de los títulos primordiales otorgada durante el virreinato de la Nueva España, estos documentos son fundamentales en la resolución de distintos juicios agrarios que los lugareños han promovido desde entonces. 


\begin{tabular}{|c|c|}
\hline $\begin{array}{c}\text { Tipos de sistemas } \\
\text { productivos }\end{array}$ & Características principales \\
\hline $\begin{array}{l}\text { Sistema } \\
\text { agroforestal } \\
\text { heredado, la milpa } \\
\text { y el maguey en la } \\
\text { memoria histórica. }\end{array}$ & $\begin{array}{l}\text { - Aprovechamiento ancestral del bosque (forestal, maderas, resinas, recolección } \\
\text { de hongos, manantiales, etc.) } \\
\text { - Siembra de policultivos (diversidad vegetal, dentro y a la orilla de la milpa). } \\
\text { - Sacralización del espacio (cuevas, manantiales, ciclo agrícola-ritual). } \\
\text { - Aprovechamiento del maguey (producción de pulque, ixtle y papel vegetal). }\end{array}$ \\
\hline $\begin{array}{l}\text { El virreinato, la } \\
\text { consolidación de } \\
\text { la ganadería, la } \\
\text { producción de } \\
\text { carbón y el sistema } \\
\text { de arrierías. }\end{array}$ & $\begin{array}{l}\text { - Fundación de la hacienda La Marquesa (introducción de } 20 \text { mil cabezas de } \\
\text { ganado menor y } 6 \text { mil de ganado mayor) } \\
\text { - Crianza, manejo y cuidado de caballos y mulas, que disponían sustituir a los } \\
\text { tamemes y consolidar el sistema de arrierías (único sistema de exportación desde } \\
\text { la dominación española hasta la introducción de ferrocarriles). } \\
\text { - Grandes producciones de carbón vegetal (Atlapulco, abastecedor oficial de } \\
\text { combustible a la Real Casa de Moneda). }\end{array}$ \\
\hline $\begin{array}{l}\text { La declaratoria del } \\
\text { Parque Nacional } \\
\text { "La Marquesa" y } \\
\text { el desarrollo de las } \\
\text { actividades de ocio } \\
\text { y recreativas. }\end{array}$ & $\begin{array}{l}\text { - El turismo aprovecha el seguido de transformaciones que ha habido en las } \\
\text { tierras de Atlapulco, desde la introducción del ganado, pasando por el carboneo y } \\
\text { otras actividades tradicionales. } \\
\text { - Crecimiento de la megalópolis que existe entre la Ciudad de México y la ciudad } \\
\text { de Toluca. } \\
\text { - Fenómenos migratorios de las zonas rurales hacia las zonas metropolitanas en } \\
\text { búsqueda de una mejor calidad de vida. }\end{array}$ \\
\hline
\end{tabular}

Cuadro 2. Síntesis de la historia económica de la comunidad agraria de San Pedro Atlapulco. Fuente: Elaboración propia.

De las actividades económicas que en Atlapulco se han realizado históricamente, la mayoría se mantuvo en el tiempo hasta la década de 1950; aún se realizaban actividades como el cultivo de la milpa y el maguey, la producción de ixtle y pulque, así como el aprovechamiento del bosque (maderas, resinas, recolección de hongos), y la producción de carbón vegetal, en menor medida; de hecho, a través de la recuperación de la memoria colectiva es posible rastrear estas actividades hasta 1980.

Actualmente, se perfila que las actividades productivas tradicionales en Atlapulco tienden a desaparecer, en contraste con las actividades terciarias como es la oferta de servicios, que en conjunto con las actividades extractivas $^{10}$ van en aumento; este panorama no es muy esperanzador para la protección de los paisajes de Atlapulco. El ocaso de las actividades tradicionales heredadas y el proceso de terciarización de la economía en la comunidad anuncian la profundización de las desigualdades socioespaciales, la pérdida de calidad ambiental en la zona y el abandono de la herencia cultural que dio origen a este pueblo.

\section{Identificación de recursos paisajísticos.}

Para la delimitación de unidades de paisaje es muy importante cartografiar y caracterizar los recursos paisajísticos, ya sean de interés ambiental, cultural o visual, estos se distinguen porque tienen algún grado de protección oficial, ya sea en escala local, regional, nacional o supranacional; pero también si son áreas o elementos del paisaje altamente valoradas por la población.

10 Minas que extraen grava, tezontle y otros materiales pétreos; de igual forma sucede con los recursos forestales e hídricos. 
Respecto a los recursos de interés ambiental (ver Ilustración 2) hemos identificado tres áreas que se catalogan dentro de las zonas de protección con decreto, dos corresponden al ámbito federal y una al estatal, ${ }^{11}$ y lo que llama la atención es que cubren casi en su totalidad el territorio comunal; las tres áreas se dirigen a la conservación ambiental de los bosques.

Entre los recursos de interés ambiental que carecen de decreto oficial identificamos una zona de fragilidad ambiental, consiste en una formación de tipo pedregal que por sus propias características es vulnerable. A pesar de que las zonas de protección decretada cubren gran parte del territorio comunal, existen elementos particulares que requieren protección especial, en este caso, las elevaciones más importantes de la zona, los ríos principales y manantiales; hemos resaltado estos elementos porque la población local indicó a partir del Taller de Ordenamiento Territorial Comunitario que son parte fundamental del funcionamiento de su territorio y paisaje.

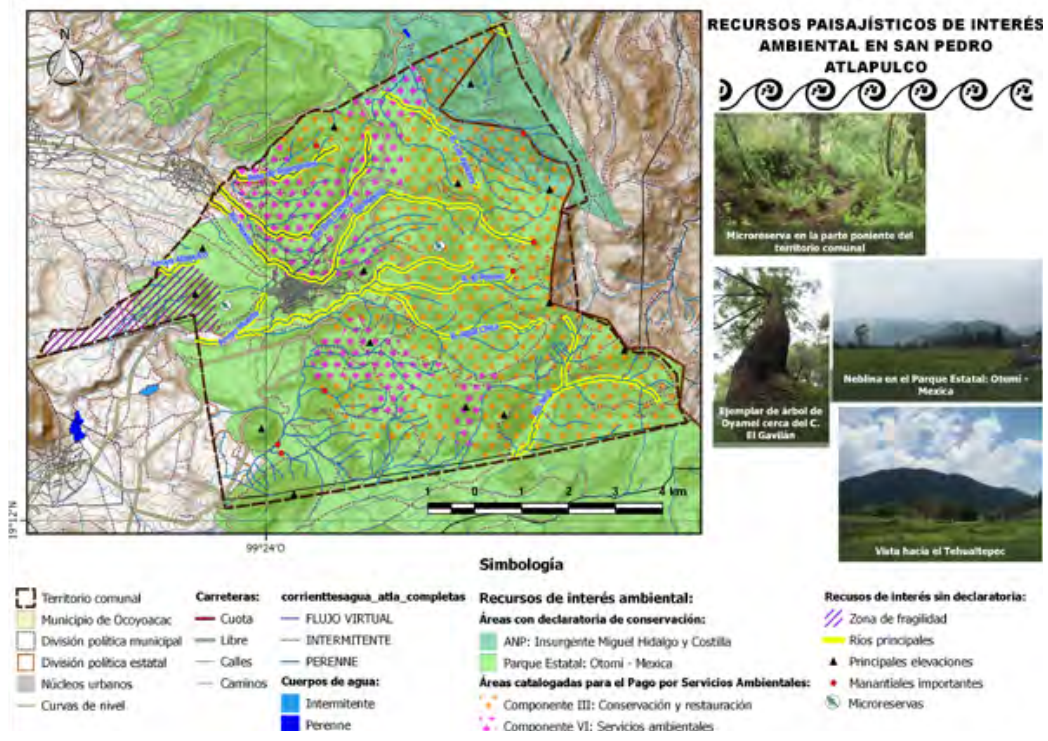

Ilustración 2. Recursos paisajísticos de interés ambiental den San Pedro Atlapulco. Fuente: Elaboración propia.

11 Las Áreas de Protección federal corresponden a: Área Natural Protegida (ANP) Insurgente Miguel Hidalgo y Costilla, conocido popularmente como "La Marquesa"; y Zonas Elegibles del Programa Pago por Servicios Ambientales, impulsado por la Comisión Nacional Forestal (CONAFOR), en este programa se clasifican dos tipos de componentes para su protección, el que ocupa mayor superficie corresponde a la categoría de Conservación y restauración, mientras que un espacio más reducido se cataloga como Servicios Ambientales, a pesar de encontrarse dentro del mismo programa, ambas áreas tienen mecanismos de gestión distintos. De carácter estatal encontramos el Parque Ecológico Turístico y Recreativo: Zempoala - La Bufa, que en el Estado de México se denomina Parque Otomí-Mexica. 
En el caso de los recursos paisajísticos de interés cultural (ver Ilustración 3), ningún elemento de los señalados se encuentra declarado con alguna categoría patrimonial o de conservación; sin embargo, definimos diversos elementos que corresponden a procesos históricos, económicos, sociales y culturales significativos.

Integramos dos tipos, uno de carácter religioso-ritual, el camino al Santuario del Señor de Chalma; y dos de carácter cultural ligado a la tradición local, los que denominamos: "Sendero de los Capulines" y "Sendero de los Tejocotes", estos caminos corresponden a dos corredores rodeados de áreas de cultivo y masas boscosas, pero que principalmente a las orillas del camino cuentan con una abundante presencia de estos dos tipos de árboles frutales nativos de México.

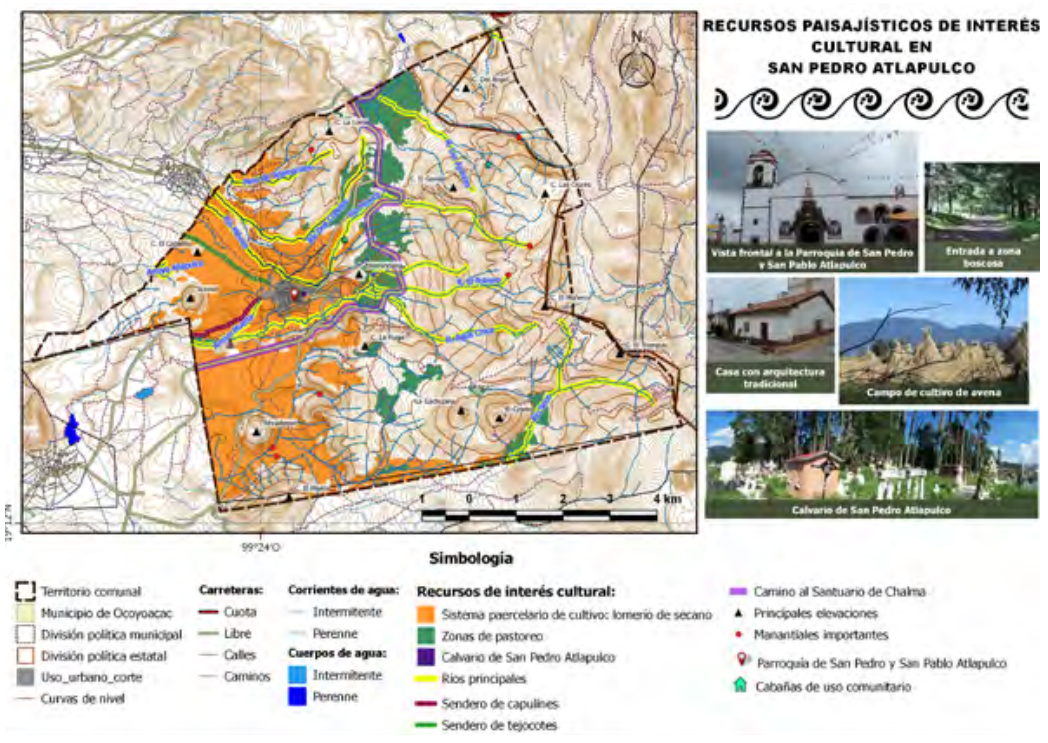

Ilustración 3. Recursos paisajísticos de interés cultural en San Pedro Atlapulco. Fuente: Elaboración propia.

Algunos de los recursos paisajísticos de interés visual (ver Ilustración 4) con mayor importancia en el territorio comunal son sin duda las distintas vistas hacia el Nevado de Toluca; sin embargo, el interés visual también lo delimitamos en los edificios volcánicos y otros elementos ubicados dentro del territorio. 


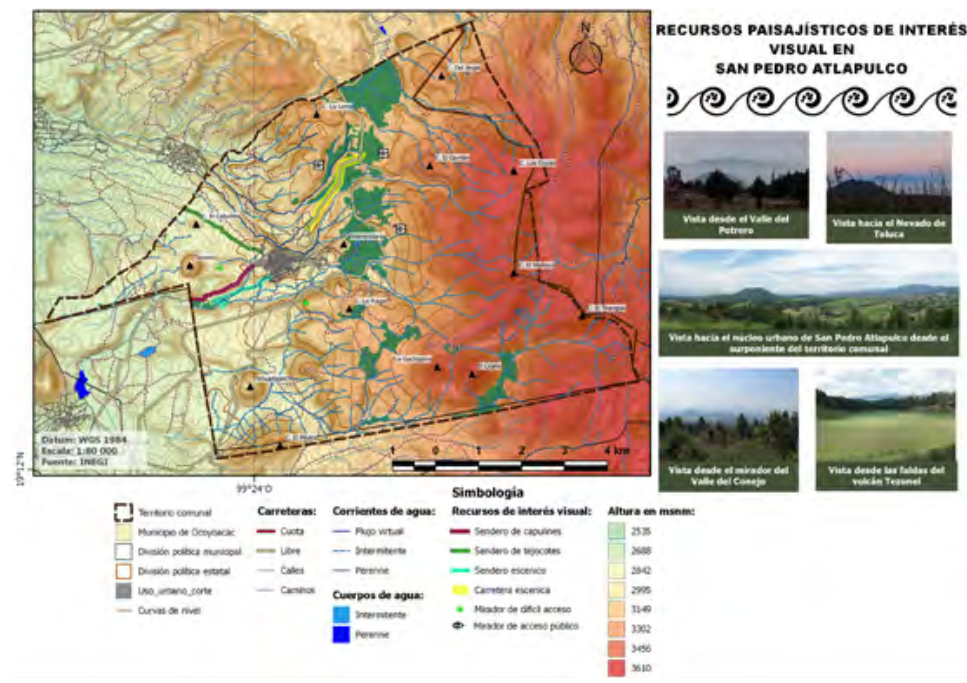

Ilustración 4. Recursos paisajísticos de interés cultural den San Pedro Atlapulco.

Fuente: Elaboración propia.

\section{Delimitación de unidades de paisaje.}

Como uno de los principales resultados delimitamos seis unidades de paisaje; por el carácter de este trabajo nos limitamos a relacionar su representación cartográfica (ver Ilustración 5) con una breve descripción de cada una (Cuadro 3), lo que nos permite una primera aproximación al reconocimiento de sus componentes.

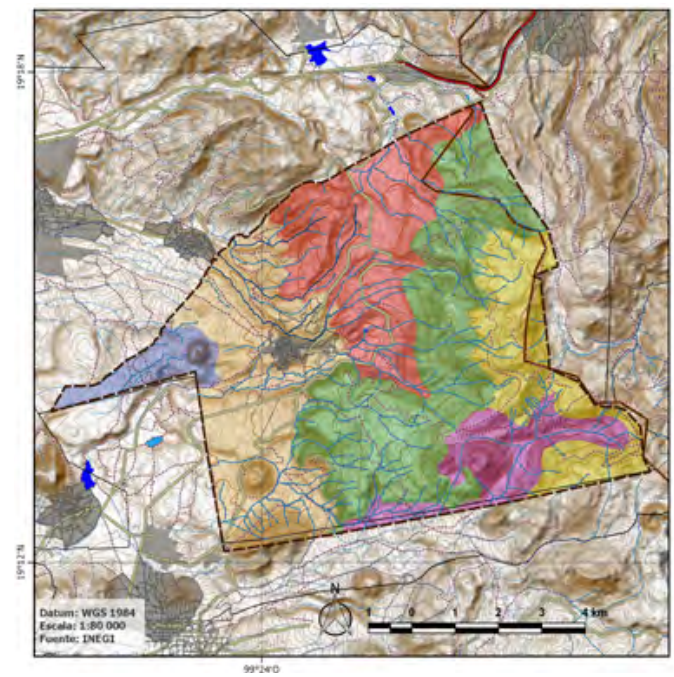

MAPA DE UNIDADES DE PAISAJE EN SAN PEDRO ATLAPULCO ) (2) (2) (2)

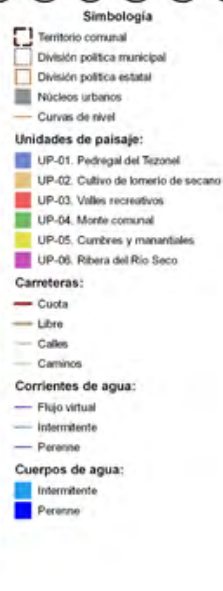

Ilustración 5. Mapa de Unidades de Paisaje en San Pedro Atlapulco. Fuente: Elaboración propia. 


\begin{tabular}{|c|c|}
\hline $\begin{array}{c}\text { Nombre de } \\
\text { la unidad de } \\
\text { paisaje }\end{array}$ & Descripción general \\
\hline $\begin{array}{l}\text { UP-01. Pedregal } \\
\text { del Tezonel }\end{array}$ & $\begin{array}{l}\text { Al extremo poniente del territorio comunal, hacia la llanura } \\
\text { de vaso lacustre de piso rocoso o cementado, se localiza } \\
\text { un ecosistema del pedregal provocado en gran medida } \\
\text { por un derrame de lava originado por la erupción del } \\
\text { volcán el Tezonel. Consideramos que es una unidad en sí } \\
\text { misma debido a su fragilidad y condiciones edafológicas, } \\
\text { de vegetación y uso de suelo muy distintas al resto del } \\
\text { territorio. }\end{array}$ \\
\hline $\begin{array}{l}\text { UP-02. Cultivo } \\
\text { de lomerío de } \\
\text { secano }\end{array}$ & $\begin{array}{l}\text { Entre los } 2,800 \text { y } 3,000 \text { msnm con suelos de tipo Cambisol y } \\
\text { Andosol ocupados principalmente por el aprovechamiento } \\
\text { agrícola tradicional, el casco urbano de Atlapulco y la zona } \\
\text { de expansión urbana hacia el paraje del Tahualtepec. El } \\
\text { sistema agrícola se combina con una leve presencia de } \\
\text { diferentes tipos de bosque: oyamel, pino, encino y pino- } \\
\text { encino. }\end{array}$ \\
\hline $\begin{array}{l}\text { UP-03. Valles } \\
\text { recreativos }\end{array}$ & $\begin{array}{l}\text { Hacia el norte del territorio comunal la zona destinada a la } \\
\text { oferta de servicios de ocio y recreativos como consecuencia } \\
\text { de la expansión del flujo de visitantes a partir de la } \\
\text { declaratoria del Parque Nacional. Esta unidad se caracteriza } \\
\text { por la presencia de pastizales que despejan la vista y } \\
\text { contrastan con las masas forestales del bosque de oyamel. } \\
\text { También es la zona del territorio que impone los usos de } \\
\text { suelo hegemónicos generando una intensa presión sobre } \\
\text { los recursos ambientales. }\end{array}$ \\
\hline $\begin{array}{l}\text { UP-04. Monte } \\
\text { comunal }\end{array}$ & $\begin{array}{l}\text { En la parte oriente del territorio y de norte a sur, entre los } \\
3,200 \text { y } 3,600 \text { msnm, con una fisiografía determinada por } \\
\text { la sierra con estrato volcanes-aislados y un tipo de suelo } \\
\text { Andosol, cubierto mayormente por un bosque denso de } \\
\text { oyamel. En esta unidad se encuentra de forma más intensa } \\
\text { la extracción de recursos forestales e hídricos del territorio } \\
\text { comunal. }\end{array}$ \\
\hline $\begin{array}{l}\text { UP-05. Cumbres } \\
\text { y manantiales }\end{array}$ & $\begin{array}{l}\text { Al extremo oriente del territorio en las zonas con mayor } \\
\text { altitud de la Sierra de Las Cruces entre los } 2,600 \text { y los } 3,870 \\
\text { msnm, encontramos de forma predominante el bosque de } \\
\text { pino y su vegetación secundaria arbustiva, la característica } \\
\text { más relevante de esta unidad es que alberga el nacimiento } \\
\text { de un gran número de manantiales y es la zona de contacto } \\
\text { entre la Cuenca del Río Lerma y la Cuenca del Río Pánuco. }\end{array}$ \\
\hline $\begin{array}{l}\text { UP-06. Ribera } \\
\text { del Río Seco }\end{array}$ & $\begin{array}{l}\text { Ubicada al sureste del territorio se caracteriza por } \\
\text { concentrar una de las zonas de infiltración hídrica más } \\
\text { importantes, con altitudes entre los } 3,500 \text { y 3,200 msnm, } \\
\text { vegetación asociada al bosque de oyamel y de pino, así } \\
\text { como una ligera ocupación de uso agrícola y pastizales. }\end{array}$ \\
\hline
\end{tabular}

Cuadro 3. Unidades de paisaje delimitadas en el territorio comunal de San Pedro Atlapulco. Fuente: Elaboración propia. 


\section{Recomendaciones para la integración de los elementos paisajísticos en San Pedro Atlapulco a la gestión territorial.}

La primera propuesta para considerar la gestión del territorio en relación con el paisaje patrimonial, es un ejercicio de superposición de la información cartográfica obtenida, colocando las unidades de paisaje (ver Ilustración 5) y los recursos paisajísticos de interés ambiental, cultural y visual (ver Ilustración 2, Ilustración 3 e Ilustración 4). El cruce de la información a primera vista nos ayuda a relacionar los elementos asociados a la dimensión patrimonial del paisaje con cada una de las unidades delimitadas.

Por ejemplo, observamos que el funcionamiento hídrico y los ríos principales tienen presencia en las seis unidades de paisaje, esto nos indica una oportunidad para coordinar la gestión hídrica entre todas las unidades; y al mismo tiempo habrá que poner atención en las unidades: UP-02. Cultivo de lomerío de secano y UP-03. Valles recreativos, ya que es en ellas donde los ríos se ven más afectados por la presión de las actividades humanas y la creciente urbanización. Por los recorridos en campo sabemos que hay una deficiencia en el manejo de los desechos afectando directamente a los ríos; entonces para estas dos unidades podría generarse una medida en lo que respecta al manejo de los desechos sólidos y líquidos para que no afecten al sistema hídrico. Al mismo tiempo poner atención en la unidad: UP-05. Cumbres y manantiales, porque es en esta unidad donde se ubica la línea divisoria de aguas de las cuencas hidrográficas que identificamos en el territorio comunal: R. Lerma y R: Pánuco, así como los límites políticos con la Ciudad de México.

De forma similar, los recursos forestales se encuentran en las seis unidades, pero se concentran en mayor medida en la unidad: UP-04. Monte comunal, y en menor medida, pero también con gran presencia en las unidades: UP-05. Cumbre y manantiales, y UP-06. Ribera del Río Seco. En este caso el mayor riesgo puede presentarse en la unidad: UP-04. Monte comunal, ya que en ella se registran más actividades de extracción tanto de madera como de recursos hídricos; el funcionamiento de esta unidad depende sustancialmente de la capacidad de infiltración hídrica de las unidades: UP-06. Ribera del Río Seco y UP-03. Valles recreativos y UP-05. Cumbres y manantiales. Por lo tanto, la sugerencia es elaborar un plan de manejo especifico en materia forestal que incluya a las seis unidades, y se ponga especial atención en las cuatro unidades señaladas.

Por su parte, el recurso paisajístico de interés cultural denominado: "Camino al Santuario de Chalma", atraviesa por tres unidades: UP-02. Cultivo de lomerío de secano, UP-03. Valles recreativos, y UP-04. Monte comunal; al mismo tiempo en estas unidades señaladas, existe una alta concentración de los recursos paisajísticos de interés visual, ambas coincidencias 
representan una oportunidad para el diseño de un plan estratégico de turismo que puede incluir un corredor panorámico.

La segunda propuesta operativa que vincula la gestión territorial con la dimensión patrimonial del paisaje, se genera al hacer una lectura de los conflictos paisajísticos, ya que por su carácter evidente pueden ser utilizados como indicadores prioritarios en las acciones y decisiones sobre el paisaje.

Desde lo anterior, en nuestro análisis identificamos tres conflictos principalmente: 1) Desaparición y degradación de los paisajes valiosos, 2) Fragmentación de los paisajes, y 3) Aparición de nuevos paisajes de baja calidad. En San Pedro Atlapulco estos conflictos se expresan en mayor medida en las unidades: UP-02. Cultivo de lomerío de secano (incluye la zona urbana del territorio) y UP-03. Valles recreativos; en ambos casos podemos encontrar los tres tipos de conflictos señalados. En el conjunto urbano, la conurbación ha derivado en la pérdida de la identidad propia del núcleo urbano y la implementación de un modelo urbanístico de baja calidad, con un carácter ajeno a la lógica del lugar a través de la sustitución sistemática de los elementos arquitectónicos, no sólo por los materiales con los que se construye sino también por las dimensiones de los edificios que en muchas ocasiones obstruyen las vistas privilegiadas que la ubicación de Atlapulco le otorga al territorio.

Otra problemática deriva de los cortes a la orografía del lugar con el objetivo de extraer arena y/o piedra de tezontle, y principalmente recursos hídricos y forestales. La extracción sin regulación puede provocar su consumo y en consecuencia la desaparición de los elementos patrimoniales más representativos de San Pedro Atlapulco.

\section{Conclusiones. El paisaje patrimonial frente a la mercantilización.}

Según los resultados de nuestra investigación consideramos que hemos logrado identificar los componentes del patrimonio paisajístico de San Pedro Atlapulco, sin embargo, en la tarea de preponderar los valores asignados por la población local al paisaje y al territorio, nos encontramos con dificultades de distinto orden que permiten abrir una discusión al respecto. Observamos que los valores están diferenciados por un factor generacional; por ejemplo, en relación a la valoración ritual del paisaje encontramos que este argumento se sostiene en un ideal, que permanece en la memoria colectiva de la comunidad pero que ha sido desplazado de las prácticas sociales y cotidianas, adoptando en su lugar una valorización 
de los elementos del paisaje como: "recursos = materia prima = dinero"12, las generaciones jóvenes de la comunidad de Atlapulco identifican como elementos con alto valor en el paisaje aquellos que les retribuyen de forma comercial, el ejemplo más emblemático es el alto valor que le asignan a los espacios destinados a la oferta de actividades de ocio y recreativas. Así mismo la extracción de recursos pétreos, hídricos, y forestales es percibida como un elemento indispensable en la valorización del territorio, que además se perciben como "infinitos".

Sin embargo, igualmente concluimos que los elementos patrimoniales de los paisajes de San Pedro Atlapulco, residen en su configuración histórica y en relación con su origen como pueblo indígena Otomí-náhuatl, entendiendo como un primer elemento patrimonial la toponimia del lugar; en segundo término, las formas de organización política, social y cultural vinculadas a un elemento clave para la protección del paisaje: la forma de tenencia de la tierra como propiedad comunal; y en tercer término su posición en el ámbito regional respecto con el camino sagrado al Santuario del Señor de Chalma. La permanencia de un flujo histórico de peregrinos que se dirigen a Chalma, representa para Atlapulco una oportunidad para rescatar su relación sagrada con el paisaje montañoso.

Nos encontramos frente a diversas formas de gestión del territorio que han convivido en la comunidad, en las cuales emerge el antagonismo entre los intereses comunitarios y los intereses individuales que se fundan en la propiedad privada. Es aquí que se visibiliza un conflicto en torno al patrimonio paisajístico o la dimensión patrimonial del paisaje, conflicto que también puede entenderse como una lucha entre la construcción de paisajes comunitarios y la mercantilización del paisaje, o bien como la posibilidad de reflexión en torno al derecho al paisaje, entendido "como la disponibilidad para el disfrute de todos los ciudadanos de entornos que contengan determinadas características y que remitan a ciertos valores y expectativas de bienestar, salud y respeto al medio ambiente" (ChecaArtasu, 2017:48).

Después de la caracterización de la dimensión patrimonial del paisaje realizada en este trabajo, deducimos que existe una valorización del paisaje en San Pedro Atlapulco, que se encuentra frente a un proceso de

12 "Al respecto es significativo el planteamiento de Vandana Shiva en relación al origen de los términos valor y recursos, donde "la palabra valor deriva del término valere, que significa ser fuerte o valioso. En las comunidades donde el agua es sagrada, la valía del líquido se sustenta en papel y función como fuerza vital para los animales, plantas y ecosistemas, sin embargo, la mercantilización del agua degrada su valor a una valía meramente comercial. (...) Al igual que el término valor, la palabra recursos también tiene un origen interesante. Proviene de la palabra recursus, que significa regreso al punto de partida. Desafortunadamente, el término actualmente define aquello que obtiene valor comercial como materia prima para la industria" (Shiva, 2002:142). 
mercantilización, generando una contradicción con los valores comunitarios asociados a las formas de apropiación y producción tradicionales del territorio. Por lo tanto, es imprescindible no dejar de lado los esfuerzos de sensibilización en torno al paisaje como un derecho. Para nuestro país, la Carta Mexicana del Paisaje (2011) y la Declaración de la Iniciativa Latinoamericana del Paisaje (LALI), firmada en 2012, son referentes útiles y adecuados para desarrollar estrategias al respecto; el paisaje es "un bien cultural, social y ambiental que representa la integración y la comunicación con el pasado de nuestros pueblos y define su devenir" (LALI, 2012:12).

Reflexionar nuestras acciones en el paisaje hoy, hacía un futuro común, nos abre posibilidades de actuación en la gestión territorial, desde una perspectiva incluyente nos permite construir a través de diálogos horizontales y la constitución de comunidades de aprendizaje, mayores conocimientos sobre la dimensión patrimonial del paisaje.

En la gestión territorial, el tratamiento a profundidad de cada una de las unidades de paisaje es un ejercicio que requiere un proceso de sensibilización y educación respecto al paisaje. Aprender a ver el paisaje de otra forma, abandonar las ideas preconcebidas, alejarnos de las escenas de postal, y vivir el paisaje siendo conscientes de las huellas que dejamos a nuestro paso.

\section{Referencias.}

Bernal G., M. y García Z., A. (2006) “El altepetl colonial y sus antecedentes prehispánicos: contexto teórico-historiográfico" en: Fernández, C., F. y García Z., Á.J. (coord.) Territorialidad y paisaje en el Altepetl del siglo XVI (pp. 31 - 113). México: FCE, Instituto de Geografía, UNAM.

Bertrand, C. y Bertrand, G. (2007). “Geografía del medio ambiente. El sistema GTP: Geosistema, Territorio y Paisaje". España: Universidad de Granada.

Capel, H. (2016). "Las ciencias sociales y el estudio del territorio". Revista bibliográfica de geografía y ciencias sociales. Vol. 21, núm. 1, 149, pp. 2 - 30. España: Universidad de Barcelona. Recuperado el 17 de marzo de 2017. http:// www.ub.edu/geocrit/b3w-1149.pdf

Cervantes H., W. (2010). "Comunalidad y Plantas Medicinales en San Pedro Atlapulco, la importancia de las Plantas Medicinales en una Comunidad Ñujhu del Alto Lerma". (tesis de licenciatura). México: Escuela Nacional de Antropología e Historia.

Checa-Artasu, M. (2014). “Oportunidades y carencias para una cultura del paisaje en México. Algunas notas" en M. Checa-Artasu, A. García Chiang, P. Soto Villagrán , P. Sunyer. (coords., 2014), Paisaje y territorio. Articulaciones teóricas y empíricas (pp. 389 - 423). México: Tirant Humanidades. Universidad Autónoma Metropolitana. 
Checa-Artasu, M. (2017). "En defensa del derecho al paisaje. Algunos ejemplos en México". En: M. Checa-Artasu, P. Sunyer Martín (coords., 2017). El paisaje: Reflexiones y métodos de análisis (pp. 45-73). México: Ediciones del Lirio, SA de CV y la Universidad Autónoma Metropolitana.

Consejo de Europa. (2000). "Convenio Europeo del Paisaje". Recuperado el 10 de junio de 2017 http://ipce.mcu.es/pdfs/convencion-florencia.pdf

Garza, G. (2010). “La transformación urbana de México, 1970-2020”. En: Desarrollo urbano y regional. Los grandes problemas de México. (Vol. 2., pp. 31-86). Garza, G. y Schteingart, M. (coords., 2010). México: El Colegio de México.

Iniciativa Latinoamericana del Paisaje. (2012). Recuperado el 15 de mayo de 2017. http://www.lali-iniciativa.com/declaracion2/

Martínez de Pisón., E. (2010). “Saber ver el paisaje”. Estudios Geográficos. Vol. LXXI, 169, Julio - diciembre, pp. 395 - 414. Consejo Superior de Investigaciones Científicas e Instituto de Economía, Geografía y Demografía. Recuperado el 3 de junio de 2017. http://estudiosgeograficos.revistas.csic.es/index.php/ estudiosgeograficos

Martínez Y., C. (2008). “Patrimonialización del territorio y territorialización del patrimonio". Cuadernos de Arte de la Universidad de Granada, 39, pp. 251-266. Recuperado el 8 de marzo de 2017. http://revistaseug.ugr.es/index.php/caug/ article/viewFile/300/291

Monterroso, N., Zizumbo, L., Monterroso, P. \& Zamorano, C. (2009). “Espoleando la esperanza. Evaluación social de la sustentabilidad en dos comunidades rurales del Estado de México". México: Porrúa/CONERSA/Universidad Autónoma del Estado de México.

Muñoz C., A. y Díez, I. (2012). “Guía metodológica. Estudios de paisaje”. España: Conselleria de Infraestructuras, Territorio y Medio Ambiente.

Ortiz, M. y Borja, B. (2008). “La investigación Acción Participativa: aporte de Fals Borda a la educación popular". Espacio Abierto, vol. 17, núm. 4, octubre diciembre, pp.651-627. Venezuela: Universidad del Zulia. Recuperado el 16 de mayo de 2018. https://www.redalyc.org/pdf/122/12217404.pdf

Santos, M. (2000). “La naturaleza del espacio", España: Ariel

Sanz H., C. (2000). “El paisaje como recurso" en: Martínez de Pisón, E. y Sanz Herráiz, C. (edit., 2000). Estudios sobre el paisaje. Colección de Estudios. España: Ediciones de la Universidad Autónoma de Madrid y Fundación Duques de Soria.

Shiva, V. (2002). "Las guerras del agua: privatización, contaminación y lucro". México: Siglo XXI.

Sunyer M, P. (2017). “Paisajes para todos. De la valorización del paisaje a su sensibilización". En: M. Checa-Artasu, P. Sunyer Martín (coords., 2017). El paisaje: Reflexiones y métodos de análisis. (pp. 21 - 44). México: Ediciones del Lirio, SA de CV y la Universidad Autónoma Metropolitana. 
Sunyer M., P. y Monterroso S., N.. (2016). “Luces y sombras en la gestión comunitaria: El caso de San Pedro Atlapulco (Ocoyoacac, Estado de México)" en XIV Coloquio Internacional de Geocrítica. Las utopías y la construcción de la sociedad del futuro. Recuperado el 17 de marzo de 2017. http://www.ub.edu/ geocrit/xiv-coloquio/SunyerMonterroso.pdf

Zoido N., F. (1998). "Geografía y ordenación del territorio". Revista Electrónica Scripta Vetera, Reproducido de: íber. España: Didáctica de las ciencias Sociales. Geografía e Historia, Barcelona Nuevas fronteras de los contenidos geográficos, pp. 19 -31. Recuperado el 15 de junio de 2017. http://www.ub.edu/geocrit/sv-77. htm.

Zoido N., F. (2012). “El paisaje un concepto útil para relacionar estética, ética y política". Scripta Nova. Revista Electrónica de Geografía y Ciencias Sociales. España: Universidad de Barcelona, 10 de julio de 2012, vol. XVI, $n^{\circ}$ 407. Recuperado el 13 de abril de 2017. http://www.ub.es/geocrit/sn/sn-407.htm 